\title{
Cognitive Function and Dialysis Adequacy: No Clear Relationship
}

\author{
Lena M. Giang ${ }^{\mathrm{a}}$ Daniel E. Weiner ${ }^{\mathrm{a}}$ Brian T. Agganis $^{\mathrm{a}}$ Tammy Scott $^{\mathrm{b}}$ \\ Eric P. Sorensen ${ }^{a}$ Hocine Tighiouart ${ }^{c}$ Mark J. Sarnak ${ }^{a}$ \\ aDivision of Nephrology, bepartment of Psychiatry, and cBiostatistics Research Center, Tufts Medical Center, \\ Boston, Mass., USA
}

\section{Key Words}

Cognitive function • Dialysis adequacy • Chronic kidney disease

\begin{abstract}
Background/Aims: Cognitive impairment is common in hemodialysis patients and may be impacted by multiple patient and treatment characteristics. The impact of dialysis dose on cognitive function remains uncertain, particularly in the current era of increased dialysis dose and flux. Methods: We explored the cross-sectional relationship between dialysis adequacy and cognitive function in a cohort of maintenance hemodialysis patients. Adequacy was defined as the average of the 3 most proximate single pool Kt/V assessments. A detailed neurocognitive battery was administered during the 1st hour of dialysis. Multivariable linear regression models were adjusted for age, sex, education, race and other clinical and demographic characteristics. Results: Among 273 patients who underwent cognitive testing, the mean (SD) age was 63 (17) years and the median dialysis duration was 13 months, 47\% were woman, 22\% were African American, and $48 \%$ had diabetes. The mean (SD) Kt/V was 1.51 (0.24). In univariate, parsimonious and multivariable models, there were no significant relationships between decreased cognitive function and lower Kt/V. Conclusion: In contrast to several older studies, there is no association between lower
\end{abstract}

$\mathrm{Kt} / \mathrm{V}$ and worse cognitive performance in the current era of increased dialysis dose. Future studies should address the longitudinal relationship between adequacy of dialysis and cognitive function to confirm these findings.

Copyright $\odot 2010$ S. Karger AG, Basel

\section{Introduction}

Cognitive impairment is highly prevalent in hemodialysis patients [1-3]. There are several potential reasons for this, including a high prevalence of cerebrovascular disease, side effects of medications, anemia and depression [4-8]. Recent epidemiologic studies have shown that cognitive impairment may be common in earlier stages of CKD and appears to become increasingly prevalent as kidney function worsens [9-13]. It remains unknown, however, whether uremia per se is an important contributor to cognitive impairment and whether higher doses of dialysis, and therefore greater solute clearance, may be associated with better cognitive function.

Several older studies have suggested a that decreased dialysis dose may be associated with worse cognitive function in hemodialysis patients, with multiple cognitive domains affected, including attention, mental processing, memory, intelligence and perceptual-motor function $[14,15]$. Conversely, other older studies and an-

\section{KARGER}

(C) 2010 S. Karger AG, Basel

Fax +4161306 1234

E-Mail karger@karger.ch

www.karger.com
Accessible online at: www.karger.com/ajn
Mark J. Sarnak, MD, MS

Tufts Medical Center, Division of Nephrology

800 Washington Street, Box 391

Boston, MA 02111 (USA)

Tel. +1 617636 1182, Fax +1 617636 8329, E-Mail msarnak@ tuftsmedicalcenter.org 
other more recent study failed to appreciate a link between dialysis adequacy and cognitive function [16-18]. Several of these studies have important limitations: the study of Kutlay et al. [16] and colleagues used only the Mini-Mental State Examination (MMSE) for cognitive assessment while Pliskin et al. [17] only studied 16 welldialyzed individuals. Tamura et al. [18] performed the most current evaluation of this question, using baseline data from the Frequent Hemodialysis Network trials. In this study, where global cognitive impairment was defined as a score $<80$ on the Modified MMSE (3MS), and impaired executive function was defined as a score $\geq 300$ s on the Trail Making Test (part B only), there was no association between dialysis adequacy and cognitive performance. The latter study, however, did not focus on dialysis adequacy. There are no studies of which we are aware that have evaluated the relationship between adequacy of dialysis and cognitive function using a detailed cognitive battery in the current era of increased dialysis dose.

\section{Methods}

\section{Participants}

All patients receiving hemodialysis at 5 Dialysis Clinic Inc. (DCI) units in the greater Boston area were considered for the Cognition and Dialysis Study. Eligibility criteria included English fluency, sufficient visual and hearing acuity to complete cognitive testing, absence of pre-existing advanced dementia or confusion (based on provider testimony or medical chart review), a medically stable condition without acute non-access-related hospitalization within the previous month, receipt of maintenance hemodialysis for at least 1 month, and single pool Kt/V (spKt/V) $>1.0$. Demographic information was obtained through participant report, medical charts and the DCI database. The Tufts Medical Center Human Investigation Review Board approved the study, and all participants signed informed consent and research authorization forms.

\section{Outcomes: Cognitive Function}

Subjects were administered a battery of cognitive tests by trained research assistants to assure quality and inter-rater reliability. Reassessment of research assistants by the study neuropsychologist (T.S.) with either mock training sessions or witnessed testing of study participants occurred at 3- to 6-month intervals. To limit subject fatigue, all testing was completed during the 1 st hour of hemodialysis. The neuropsychological battery included well-validated and commonly used cognitive tests that possess high inter- and intrarater reliability and have established age, gender and education-matched normative scores. Tests included the MMSE [19], the North American Adult Reading Test [20], the Wechsler Memory Scale-III Word List Learning Subtest [21], the Wechsler Adult Intelligence Scale-III Block Design and Digit Symbol-Coding tasks [21], and Trail Making Tests A and B [22] (online suppl. table 1, www.karger.com/doi/10.1159/000322611). The overall battery assessed a broad range of functioning including global ability, verbal intelligence, supraspan learning, auditory retention, visual retention, attention/mental processing speed, visual construction/fluid reasoning and motor speed.

\section{Exposure: $\mathrm{Kt} / \mathrm{V}$}

Adequacy of dialysis was quantified by spKt/V. The value for spKt/V was obtained from the monthly charts of the DCI electronic database. In order to improve the appropriate classification of the exposure variable, an average of the 3 most proximate $\mathrm{spKt} / \mathrm{V}$ values for each participant was used.

\section{Statistical Analysis}

Baseline characteristics of eligible dialysis patients who consented and did not consent to participate were compared using $\chi^{2}$ tests, $\mathrm{t}$ tests and ANOVA as appropriate. Similarly, baseline characteristics of participants enrolled in the study were compared by sex-specific quartiles of spKt/V. Primary analyses used linear regression to explore the association of $\mathrm{spKt} / \mathrm{V}$ with performance on individual cognitive tests, with the raw test scores serving as the dependent variables. Kt/V was modeled linearly with parameter estimates ( $\beta$-coefficients) calculated per 1 SD increase and also using sex-specific quartiles to assess for nonlinear relationships. Analyses where performance on the Trails B test was the outcome used Tobit regression, censoring for failure to complete the task within 5 min [23]. Parsimonious models were adjusted a priori for age, sex, race (African American vs. non-African American) and education (did not graduate high school, high school graduate and/or 1 year of college, 2+ years of college). Fully adjusted models were further adjusted for cause of ESRD, dialysis vintage, BMI, history of smoking, history of cardiovascular disease, hematocrit and albumin. Secondary analyses explored this association using sex-specific quartiles of spKt/V, reflecting the findings from the HEMO Study, which suggested there may be a different effect of adequacy on mortality in men and women, and recognizing that there are frequently inherent differences in the ability to achieve Kt/V targets by sex [24-26]. Finally, in sensitivity analyses we examined the association between spKt/V and cognitive performance in separate models for men and women. All analyses were performed using SAS, version 9.2 (SAS Institute, Cary, N.C., USA); differences were considered statistically significant at $\mathrm{p}<0.05$.

\section{Results}

Among the 753 dialysis patients who were screened, 430 were eligible for the study. Of the eligible patients, 280 consented and 273 completed the testing. Eligible patients not enrolled were similar to those who were enrolled across all measured characteristics, including age, race, sex, dialysis vintage and primary cause of ESRD, with the exception of lower phosphate [mean (SD): 5.1 (1.5) $\mathrm{mg} / \mathrm{dl}]$, serum albumin [3.7 (0.5) $\mathrm{mg} / \mathrm{dl}]$ and intact parathyroid hormone [median: $196 \mathrm{pg} / \mathrm{ml}$ (interquartile range: 126-300)] in eligible patients who did not consent. 
Table 1. Characteristics of participants by sex-specific quartiles of spKt/V

\begin{tabular}{|c|c|c|c|c|c|c|}
\hline & $\begin{array}{l}\text { Total } \\
(n=273)\end{array}$ & $\begin{array}{l}\mathrm{Kt} / \mathrm{V}, \mathrm{Q} 1 \\
(\mathrm{n}=68)\end{array}$ & $\begin{array}{l}\mathrm{Kt} / \mathrm{V}, \mathrm{Q} 2 \\
(\mathrm{n}=68)\end{array}$ & $\begin{array}{l}\mathrm{Kt} / \mathrm{V}, \mathrm{Q} 3 \\
(\mathrm{n}=68)\end{array}$ & $\begin{array}{l}\mathrm{Kt} / \mathrm{V}, \mathrm{Q} 4 \\
(\mathrm{n}=69)\end{array}$ & $\begin{array}{l}\text { Trend } \\
\text { p value }\end{array}$ \\
\hline Age, years & $63 \pm 17$ & $60 \pm 17$ & $63 \pm 16$ & $67 \pm 15$ & $64 \pm 18$ & 0.099 \\
\hline Female & 47 & 47 & 47 & 48 & 47 & 0.932 \\
\hline African American & 22 & 24 & 31 & 16 & 16 & 0.092 \\
\hline Education & & & & & & 0.045 \\
\hline$<12$ th grade & 10 & 16 & 4 & 4 & 13 & \\
\hline High school graduate & 58 & 49 & 69 & 56 & 59 & \\
\hline $2+$ years college & 32 & 35 & 26 & 40 & 28 & \\
\hline \multicolumn{7}{|l|}{ Medical history } \\
\hline Peripheral vascular disease & 22 & 25 & 15 & 29 & 19 & 0.862 \\
\hline Coronary artery disease & 33 & 28 & 29 & 41 & 35 & 0.207 \\
\hline Hypertension & 87 & 82 & 90 & 88 & 88 & 0.357 \\
\hline Stroke & 20 & 22 & 18 & 21 & 19 & 0.755 \\
\hline Diabetes & 48 & 56 & 54 & 46 & 35 & 0.008 \\
\hline Heart failure & 34 & 34 & 37 & 35 & 30 & 0.647 \\
\hline Primary cause of ESRD & & & & & & 0.042 \\
\hline Diabetes & 37 & 44 & 45 & 40 & 19 & \\
\hline Glomerulonephritis & 18 & 21 & 11 & 12 & 28 & \\
\hline Hypertension & 20 & 12 & 20 & 21 & 26 & \\
\hline Other & 19 & 16 & 17 & 19 & 23 & \\
\hline Unknown & 7 & 7 & 8 & 9 & 4 & \\
\hline Smoking history & & & & & & 0.034 \\
\hline Never & 38 & 40 & 39 & 32 & 40 & \\
\hline Past & 55 & 52 & 46 & 68 & 52 & \\
\hline Current & 8 & 8 & 15 & 0 & 8 & \\
\hline $\mathrm{spKt} / \mathrm{V}$ & $1.51 \pm 0.24$ & $1.25 \pm 0.10$ & $1.42 \pm 0.09$ & $1.56 \pm 0.09$ & $1.79 \pm 0.19$ & $<0.001$ \\
\hline Systolic BP, mm Hg & $143 \pm 21$ & $142 \pm 22$ & $146 \pm 20$ & $141 \pm 20$ & $142 \pm 21$ & 0.713 \\
\hline Diastolic BP, mm Hg & $73 \pm 12$ & $75 \pm 14$ & $74 \pm 2$ & $71 \pm 11$ & $73 \pm 12$ & 0.163 \\
\hline BMI $\left(\mathrm{kg} / \mathrm{m}^{2}\right)$ & $28 \pm 7$ & $31 \pm 9$ & $29 \pm 6$ & $27 \pm 6$ & $26 \pm 6$ & $<0.001$ \\
\hline Hematocrit, \% & $36 \pm 3$ & $36 \pm 4$ & $36 \pm 3$ & $35 \pm 3$ & $35 \pm 3$ & 0.020 \\
\hline Serum albumin, g/dl & $3.8 \pm 0.3$ & $3.8 \pm 0.4$ & $3.9 \pm 0.3$ & $3.9 \pm 0.4$ & $3.9 \pm 0.3$ & 0.061 \\
\hline Phosphate, mg/dl & $5.5 \pm 1.5$ & $5.8 \pm 1.9$ & $5.3 \pm 1.5$ & $5.1 \pm 1.2$ & $5.5 \pm 1.4$ & 0.463 \\
\hline Dialysis vintage, months & $13(6-32)$ & $9(4-19)$ & $12(5-28)$ & $17(10-38)$ & $19(11-39)$ & $<0.001$ \\
\hline $\mathrm{PTH}, \mathrm{pg} / \mathrm{ml}$ & $223(143-390)$ & $226(129-414)$ & $227(141-332)$ & $217(152-343)$ & $225(145-403)$ & 0.996 \\
\hline
\end{tabular}

Continuous data shown are means $\pm \mathrm{SD}$, except dialysis vintage and PTH which are medians (interquartile range); categorical data are presented as percentages. $\mathrm{p}$ values for education, primary cause of ESRD and smoking are from a $\chi^{2}$ test. $p$ values for dialysis vintage and PTH are from the Kruskal-Wallis test. Conversion factors for units: albumin in g/dl to g/l, multiply by 10; phosphate in $\mathrm{mg} / \mathrm{dl}$ to $\mathrm{mmol} / \mathrm{l}$, multiply by 0.3229 . $\mathrm{BP}=$ Blood pressure; $\mathrm{PTH}=$ parathyroid hormone .

The mean (SD) age of enrolled participants was 63 (17) years; $47 \%$ were female, $22 \%$ African American, $48 \%$ had diabetes and the median (interquartile range) of dialysis vintage was 13 months (6-32). Mean (SD) Kt/V was 1.51 (0.24) (table 1).

We noted no consistent relationship between lower levels of $\mathrm{Kt} / \mathrm{V}$ and worse cognitive function (table 2). In fact, participants with higher Kt/V performed significantly worse on the MMSE in univariate linear regression analyses and after parsimonious and multivariable ad- justments. Participants with higher Kt/V also had worse performance in the recognition task after parsimonious and multivariable adjustments (table 2). Results were consistent using sex-specific quartiles with no association between lower levels of $\mathrm{Kt} / \mathrm{V}$ and worse cognitive function. The sex-specific quartile analyses demonstrated worse performance on the MMSE with higher Kt/V, when evaluating the unadjusted means (table 3). Results were consistent in sex-specific quartiles examining the $\beta$-coefficients after multivariable adjustments (table 3 ). 
Table 2. Cognitive testing by Kt/V

\begin{tabular}{|c|c|c|c|c|c|c|c|}
\hline \multirow[t]{2}{*}{ Cognitive test } & \multirow[t]{2}{*}{ Function tested } & \multicolumn{2}{|l|}{ Univariate } & \multicolumn{2}{|c|}{ Parsimonious } & \multicolumn{2}{|c|}{ Multivariable } \\
\hline & & $\beta$-coefficient & $\mathrm{p}$ value & $\beta$-coefficient & $\mathrm{p}$ value & $\beta$-coefficient & $\mathrm{p}$ value \\
\hline MMSE & screen & -0.45 & 0.010 & -0.57 & 0.001 & -0.48 & 0.012 \\
\hline NAART & intelligence & 0.04 & 0.958 & -0.57 & 0.413 & -0.95 & 0.220 \\
\hline Percent retention & primary cortical (memory) & -1.12 & 0.519 & -2.69 & 0.126 & -1.32 & 0.510 \\
\hline Recognition & & -0.29 & 0.116 & -0.47 & 0.007 & -0.46 & 0.024 \\
\hline Block design & primary subcortical & -0.56 & 0.396 & -0.59 & 0.327 & -0.13 & 0.843 \\
\hline Digit symbol coding & (executive function and & 0.72 & 0.524 & -0.68 & 0.462 & -0.61 & 0.546 \\
\hline Trails A & processing speed) & 0.37 & 0.876 & 1.68 & 0.472 & 0.60 & 0.820 \\
\hline Trails B & & 1.28 & 0.857 & 7.12 & 0.255 & 1.50 & 0.823 \\
\hline
\end{tabular}

Results represent per 1 SD (0.24) increase in Kt/V. Trails B analyses were performed using Tobit regression to account for failure to complete the task within $5 \mathrm{~min}$. Negative $\beta$-coefficients indicate worse performance associated with high $\mathrm{Kt} / \mathrm{V}$ for all tests except Trials A and B where a positive score indicates worse per- formance. Parsimonious models adjust for age, sex, race and education while full multivariable models additionally adjust primary cause of ESRD, dialysis vintage, BMI, history of smoking, history of cardiovascular disease, hematocrit and albumin. NAART $=$ North American Adult Reading Test.

Table 3. Univariate means and multivariable $\beta$-coefficients for cognitive testing by sex-specific quartiles of Kt/V

\begin{tabular}{|c|c|c|c|c|c|c|c|c|c|c|}
\hline \multirow[t]{2}{*}{ Cognitive test } & \multirow[t]{2}{*}{ Function tested } & \multicolumn{5}{|c|}{$\begin{array}{l}\text { Univariate means by } \\
\text { sex-specific Kt/V quartiles }\end{array}$} & \multicolumn{4}{|c|}{$\begin{array}{l}\text { Multivariable } \beta \text {-coefficients by } \\
\text { sex-specific Kt/V quartiles }\end{array}$} \\
\hline & & Kt/V Q1 & Kt/V Q2 & Kt/V Q3 & Kt/V Q4 & $\begin{array}{l}\text { trend } \\
\mathrm{p} \text { value }\end{array}$ & Kt/V Q1 & Kt/V Q2 & Kt/V Q3 & $\begin{array}{l}\text { trend } \\
\mathrm{p} \text { value }\end{array}$ \\
\hline MMSE & screen & 27.1 & 26.6 & 26.9 & 25.8 & 0.007 & 1.03 & 1.00 & 1.07 & 0.056 \\
\hline NAART & intelligence & 101.8 & 103.2 & 102.5 & 100.5 & 0.474 & 3.21 & 4.91 & 1.49 & 0.051 \\
\hline Percent retention & primary cortical & 55.8 & 52.0 & 52.9 & 49.5 & 0.251 & 0.17 & 0.71 & 1.68 & 0.983 \\
\hline Recognition & (memory) & 21.0 & 21.1 & 21.0 & 20.0 & 0.062 & 0.74 & 1.43 & 1.15 & 0.144 \\
\hline Block design & & 26.3 & 28.0 & 24.8 & 26.4 & 0.604 & -1.37 & 1.84 & -0.84 & 0.771 \\
\hline Digit-symbol coding & primary subcortical & 42.4 & 40.1 & 37.8 & 40.7 & 0.440 & 0.19 & 1.42 & -0.11 & 0.810 \\
\hline Trails A & (executive and & 58.0 & 59.4 & 60.6 & 64.0 & 0.368 & -2.92 & -5.98 & -6.16 & 0.692 \\
\hline Trails B & processing speeds) & 172.5 & 177.4 & 209.4 & 178.2 & 0.435 & 7.63 & -9.83 & 16.42 & 0.986 \\
\hline
\end{tabular}

Results represent the mean raw score by sex-specific Kt/V quartiles and $\beta$-coefficient by sex-specific quartiles. Trails B analyses were performed using Tobit regression to account for failure to complete the task within $5 \mathrm{~min}$. $\beta$-Coefficients by sex-specific quartiles are in reference to Kt/V, Q4. Minimum and maximum
spKt/V for each quartile by sex - men: Q1 (0.97-1.28), Q2 (1.291.41), Q3 (1.42-1.54), Q4 (1.55-1.96); women: Q1 (1.06-1.43), Q2 (1.43-1.58), Q3 (1.58-1.73), Q4 (1.73-2.56). NAART = North American Adult Reading Test.
In the sensitivity analyses stratified by sex, there was no association between lower levels of Kt/V and worse cognitive function in either men or women (data not shown). However, in men in both univariate and parsimonious models, those with higher $\mathrm{Kt} / \mathrm{V}$ performed worse in the MMSE ( $\beta$-coefficient $=-0.57, p=0.018$; $\beta$-coefficient $=-0.64, p$ value $=0.005$, respectively). This finding was not seen in women.

\section{Discussion}

In maintenance hemodialysis patients, we saw no evidence that lower levels of dialysis adequacy are associated with worse function on memory or executive function. In fact, we noted that testing of global cognitive function, measured by the MMSE, and recognition were slightly worse in those with higher Kt/V levels, although this finding was inconsistent across cognitive domains. 
These results suggest that, in the current era of increased dialysis dose, there is no association of higher $\mathrm{Kt} / \mathrm{V}$ with better cognitive function. Our results are consistent with a recent study from the Frequent Hemodialysis Network (FHN) trials where cognitive function was evaluated in 383 relatively healthy dialysis participants. In that particular study, the 3MS and Trails B were used as indicators of global cognitive function and executive function, respectively. Results showed that higher, rather than lower, Kt/V was significantly associated with worse cognitive performance on Trails B, but there was no relationship of Kt/V with the 3MS. In combination, both studies are consistent with the absence of an association of higher levels of cognitive function with higher Kt/V. The current study, however, adds to the FHN study by evaluating a more comprehensive battery of cognitive tests, focusing exclusively on the relationship between cognitive function and $\mathrm{Kt} / \mathrm{V}$ rather than on multiple risk factors for cognitive impairment, and in using a more generalizable population.

The paradoxical finding of better cognitive function in those with lower Kt/V in the FHN study and with recognition in our current study most likely reflects residual confounding. That is, patients who able to achieve high $\mathrm{Kt} / \mathrm{V}$ are usually underweight and more malnourished [27]. Frequently, these patients are also more susceptible to toxicity caused by more intensive dialysis, have more comorbid conditions, are sicker and, therefore, are more likely to have worse cognitive function $[28,29]$.

Our study has several strengths. First, the extensive and detailed neurocognitive evaluation allowed us to examine the relationship between dialysis adequacy and several cognitive domains. Second, we had a relatively large sample with minimal exclusion criteria. This led to relatively generalizable population with participants having characteristics and distribution of causes of ESRD similar to those found in the prevalent US dialysis population [30].
Our study also has several limitations. First, as alluded to above, because of the observational nature of the study, residual confounding may be present. Second, our study only included patients with $s p K t / V \geq 1$; therefore, we cannot comment on whether levels below those are associated with worse cognitive function. Third, cognitive testing was performed on hemodialysis, which may lead to slightly worse performance on cognitive testing [31]. Testing during dialysis, however, should not alter the relationship between $\mathrm{Kt} / \mathrm{V}$ and cognitive function, the primary outcome of this study. Furthermore, although there may be a downside to assessing patients during hemodialysis, it does have the advantage of testing patients in the same environment where they are likely to receive most of the medical counseling from physicians, nurses and nutritionist providers. Finally the study was cross-sectional and we cannot rule out an association of higher $\mathrm{Kt} / \mathrm{V}$ with higher levels of cognitive function in prospective analyses.

In summary, in the current era of increased dialysis dose, we have not demonstrated any association between higher achieved dialysis dose and better performance on any measure of cognitive testing. Future research should confirm these results in longitudinal analyses.

\section{Acknowledgements}

We would like to acknowledge the tremendous assistance of Dialysis Clinic Inc. and, in particular, the staff of the 5 DCI units in the Boston area, without whose cooperation the study would not have been successful. This manuscript was presented in abstract form at the American Society of Nephrology Annual Meeting in San Diego in 2009.

\section{Disclosure Statement}

The study was funded through NIH grants R21 DK068310, K23 DK071636, K24 DK078204 and R01 DK078204. The authors have no conflicts of interest to declare.

\section{References}

1 Murray AM, Tupper DE, Knopman DS, Gilbertson DT, Pederson SL, Li S, Smith GE, Hochhalter AK, Collins AJ, Kane RL: Cognitive impairment in hemodialysis patients is common. Neurology 2006;67:216-223.

2 Pereira AA, Weiner DE, Scott T, Chandra P, Bluestein R, Griffith J, Sarnak MJ: Subcortical cognitive impairment in dialysis patients. Hemodial Int 2007;11:309-314.
3 Sehgal AR, Grey SF, DeOreo PB, Whitehouse PJ: Prevalence, recognition, and implications of mental impairment among hemodialysis patients. Am J Kidney Dis 1997;30:4149.

4 Madero M, Gul A, Sarnak MJ: Cognitive function in chronic kidney disease. Semin Dial 2008;21:29-37.
5 Pereira AA, Weiner DE, Scott T, Sarnak MJ: Cognitive function in dialysis patients. Am J Kidney Dis 2005;45:448-462.

6 Uzu T, Kida Y, Shirahashi N, Harada T, Yamauchi A, Nomura M, Isshiki K, Araki S, Sugimoto T, Koya D, Haneda M, Kashiwagi A, Kikkawa R: Cerebral microvascular disease predicts renal failure in type 2 diabetes. J Am Soc Nephrol 2010;21:520-526. 
7 McClellan W, Aronoff SL, Bolton WK, Hood S, Lorber DL, Tang KL, Tse TF, Wasserman B, Leiserowitz M: The prevalence of anemia in patients with chronic kidney disease. Curr Med Res Opin 2004;20:1501-1510.

$\checkmark 8$ Delmez JA, Yan G, Bailey J, Beck GJ, Beddhu S, Cheung AK, Kaysen GA, Levey AS, Sarnak MJ, Schwab SJ: Cerebrovascular disease in maintenance hemodialysis patients: results of the HEMO Study. Am J Kidney Dis 2006; 47:131-138.

-9 Bremer BA, Wert KM, Durica AL, Weaver A: Neuropsychological, physical, and psychosocial functioning of individuals with endstage renal disease. Ann Behav Med 1997;19: 348-352.

10 Kurella M, Chertow GM, Luan J, Yaffe K: Cognitive impairment in chronic kidney disease. J Am Geriatr Soc 2004;52:18631869.

- 11 Kurella M, Luan J, Yaffe K, Chertow GM: Validation of the Kidney Disease Quality of Life (KDQOL) cognitive function subscale. Kidney Int 2004;66:2361-2367.

>12 Kurella M, Yaffe K, Shlipak MG, Wenger NK, Chertow GM: Chronic kidney disease and cognitive impairment in menopausal women. Am J Kidney Dis 2005;45:66-76.

$\checkmark 13$ Yaffe K, Ackerson L, Kurella Tamura M, Le Blanc P, Kusek JW, Sehgal AR, Cohen D, Anderson C, Appel L, Desalvo K, Ojo A, Seliger S, Robinson N, Makos G, Go AS: Chronic kidney disease and cognitive function in older adults: findings from the chronic renal insufficiency cohort cognitive study. J Am Geriatr Soc 2010;58:338-345.

-14 Hart RP, Pederson JA, Czerwinski AW, Adams RL: Chronic renal failure, dialysis, and neuropsychological function. J Clin Neuropsychol 1983;5:301-312.

-15 Umans JG, Pliskin NH: Attention and mental processing speed in hemodialysis patients. Am J Kidney Dis 1998;32:749-751.
16 Kutlay S, Nergizoglu G, Duman N, Atli T, Keven K, Erturk S, Ates K, Karatan O: Recognition of neurocognitive dysfunction in chronic hemodialysis patients. Ren Fail 2001;23:781-787.

17 Pliskin NH, Yurk HM, Ho LT, Umans JG: Neurocognitive function in chronic hemodialysis patients. Kidney Int 1996;49:14351440 .

18 Tamura MK, Larive B, Unruh ML, Stokes JB, Nissenson A, Mehta RL, Chertow GM: Prevalence and correlates of cognitive impairment in hemodialysis patients: the frequent hemodialysis network trials. Clin J Am Soc Nephrol 2010;5:1429-1438.

19 Folstein MF, Folstein SE, McHugh PR 'Mini-mental state'. A practical method for grading the cognitive state of patients for the clinician. J Psychiatr Res 1975;12:189-198.

20 Uttl B: North American adult reading test: age norms, reliability, and validity. J Clin Exp Neuropsychol 2002;24:1123-1137.

21 Tulsky D, Zhu K, Lebetter M: Wechsler Adult Intelligence Scale-Third Edition (WAIS-III), Wechsler Memory Scale-Third Scale (WMS III): Technical Manual. San Antonio, Harcourt Brace and Company, 1997.

22 Heaton RK, Grant I, Matthews CG: Comprehensive Norms for an Expanded HalsteadReitan Battery. Odessa, Psychological Assessment Resources, 1991.

23 Tobin J: Estimation for relationships with limited dependent variables. Econometrica 1958;26:24-36.

24 Elangovan L, Shinaberger CS, Kraut JA, Shinaberger JH: Hemo equilibrated Kt/V goals are difficult to achieve in large male patients. ASAIO J 2001;47:235-239.
25 Eknoyan G, Beck GJ, Cheung AK, Daugirdas JT, Greene T, Kusek JW, Allon M, Bailey J, Delmez JA, Depner TA, Dwyer JT, Levey AS, Levin NW, Milford E, Ornt DB, Rocco MV, Schulman G, Schwab SJ, Teehan BP, Toto R: Effect of dialysis dose and membrane flux in maintenance hemodialysis. N Engl J Med 2002;347:2010-2019.

-26 Owen WF Jr, Chertow GM, Lazarus JM, Lowrie EG: Dose of hemodialysis and survival: differences by race and sex. JAMA 1998;280:1764-1768.

27 Salahudeen AK, Fleischmann EH, Bower JD: Impact of lower delivered $\mathrm{Kt} / \mathrm{V}$ on the survival of overweight patients on hemodialysis. Kidney Int 1999;56:2254-2259.

28 Chertow GM, Owen WF, Lazarus JM, Lew NL, Lowrie EG: Exploring the reverse Jshaped curve between urea reduction ratio and mortality. Kidney Int 1999;56:18721878

29 Salahudeen AK, Dykes P, May W: Risk factors for higher mortality at the highest levels of spKt/V in haemodialysis patients. Nephrol Dial Transplant 2003;18:1339-1344.

$>30$ Collins AJ, Foley RN, Herzog C, Chavers BM, Gilbertson D, Ishani A, Kasiske BL, Liu J, Mau LW, McBean M, Murray A, St Peter W, Guo H, Li Q, Li S, Peng Y, Qiu Y, Roberts T, Skeans M, Snyder J, Solid C, Wang C, Weinhandl E, Zaun D, Arko C, Chen SC, Dalleska F, Daniels F, Dunning S, Ebben J, Frazier E, Hanzlik C, Johnson R, Sheets D, Wang X, Forrest B, Constantini E, Everson S, Eggers PW, Agodoa L: Excerpts from the US Renal Data System 2009 Annual Data Report. Am J Kidney Dis 2010;55:S1-420, A426-A427.

-31 Murray AM, Pederson SL, Tupper DE, Hochhalter AK, Miller WA, Li Q, Zaun D, Collins AJ, Kane R, Foley RN: Acute variation in cognitive function in hemodialysis patients. A cohort with repeated measures. Am J Kidney Dis 2007;50:270-278. 